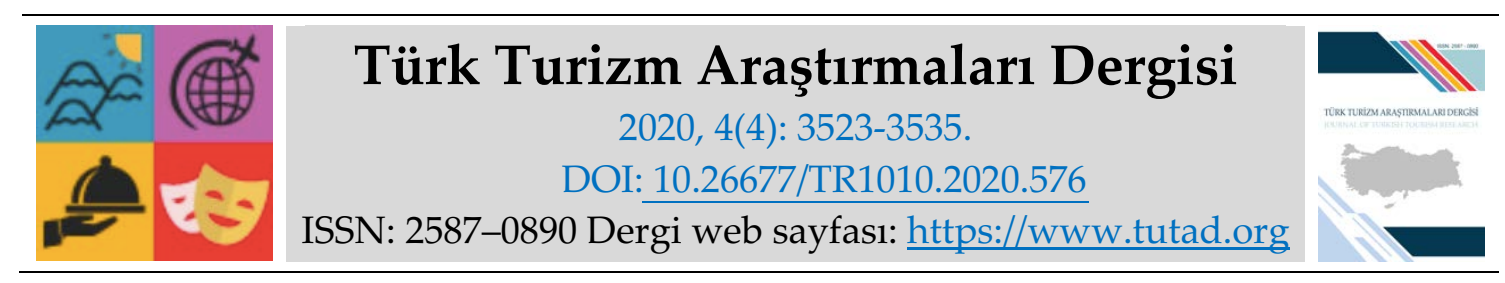

ARAȘTIRMA MAKALESI

\title{
Doğa Temelli Turizm Kapsamında Narman Peri Bacaları Ziyaretçi Yorumlarının İçerik Analizi ile İncelenmesi
}

Dr. Öğr. Üyesi Ali İSKENDER, Atatürk Üniversitesi, Turizm Fakültesi, Erzurum, e-posta: ali.iskender@atauni.edu.tr

ORCID: https://orcid.org/0000-0003-2753-1242

Öz

Narman Peri Bacaları Erzurum'un başlıca doğa temelli turizm destinasyonlarından biridir. Bu araştırmada Narman Peri Bacalarını ziyaret eden kişilerin sosyal medya araçları üzerinden deneyimlerine yönelik yaptıkları yorumlar incelenmiştir. Elde edilen sonuçlar doğrultusunda destinasyonla ilgili çeşitli öneriler geliştirilmiştir. Mevcut çalışma nitel bir araştırma olup durum araştırması özelliği taşımaktadır. NVIVO 12 programı kullanılarak ziyaretçilerin yorumları kategorilere ayrılmıştır. Yorumlar iki ana temadan oluşmuştur. Oluşturulan temalar ziyaretçilerin olumlu görüşlerini içeren olumlu izlenimler ana teması ve olumsuz görüşlerini içeren eleştiri ana temasıdır. Her iki ana tema iki alt temadan oluşmaktadır. Olumsuz görüşler teması, 30 eleştiri içerikli yorumdan oluşmaktadır. Bu eleştirilerden 11'i destinasyona yönelik iken diğer 19 eleştiri ise idarecilere yönelik olarak iletilmiştir. Araştırma sonucunda ziyaretçilerin destinasyonla ilgili özellikle tanıtım ve tesis eksikliği hususlarında eleştireler yönelttiği sonucuna varılmıştır. Olumlu izlenimler teması ile ilgili olarak ise toplam 88 yorum bulunmaktadır. Bu yorumların 44 'ü bölgeyi diğer ziyaretçilere tavsiye eden yorumlardan oluşurken diğer 44 yorum bölgeyi öven yorum içeriklerinden oluşmaktadır.

Anahtar Kelimeler: Narman, Peri Bacaları, Ziyaretçi.

Makale Gönderme Tarihi: 01.06.2020

Makale Kabul Tarihi: 08.10.2020

\section{Önerilen Atıf:}

İskender, A. (2020). Doğa Temelli Turizm Kapsamında Narman Peri Bacaları Ziyaretçi Yorumlarını İçerik Analizi ile İncelenmesi, Türk Turizm Araştırmaları Dergisi, 4(4): 3523-3535.

(c) 2020 Türk Turizm Araştırmaları Dergisi. 


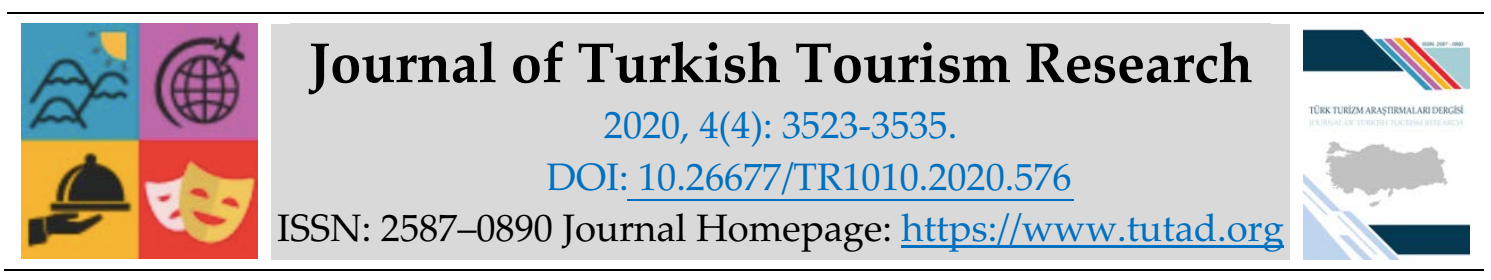

\title{
$\underline{\text { RESEARCH PAPER }}$
}

\section{Within the Scope of Nature Based Tourism: A Study of Visitor Comments on Narman Fairy Chimneys by Content Analysis}

Assistant Prof. Dr. Ali İSKENDER, Atatürk University, Faculty of Tourism, Erzurum, e-mail: ali.iskender@atauni.edu.tr ORCID: https://orcid.org/0000-0003-2753-1242

\begin{abstract}
Narman Fairy Chimneys is one of Erzurum's main nature-based tourism destinations. In this study, the comments made by people who visited Narman Fairy Chimneys about their experiences on social media tools were examined. Various suggestions about the destination have been developed in line with the results obtained. The current study is a qualitative research and it is a case study. Visitors' comments were divided into categories using the NVIVO 12 program. The comments consisted of two main themes. The themes created are the main theme of positive impressions, including the positive opinions of the visitors, and the main theme of criticism, which includes negative opinions. Both main themes consist of two sub-themes. Negative opinions theme consists of 30 critical comments. While 11 of these criticisms were directed to the destination, the other 19 criticisms were conveyed to the administrators. As a result of the research, it was concluded that the visitors criticized the destination especially about the promotion and lack of facilities. There is a total of 88 comments on the theme of positive impressions. 44 of these comments consist of comments recommending the region to other visitors, while the other 44 comments consist of comments praising the region. It contains the opinions of the visitors indicating their satisfaction from the region.
\end{abstract}

Keywords: Narman, Fairy Chimneys, Visitor.

Received: 01.06.2020

Accepted: 08.10.2020

\section{Suggested Citation:}

İskender, A. (2020). Within the Scope of Nature Based Tourism: A Study of Visitor Comments on Narman Fairy Chimneys by Content Analysis, Journal of Turkish Tourism Research, 4(4): 3523-3535. (C) 2020 Türk Turizm Araştırmaları Dergisi. 


\section{Gíriş}

Türkiye'de turizm özellikle 1980 yllı itibariyle büyük bir ivme kazanarak ülke ekonomisine bugüne kadar ciddi destekler sağlamıştır (Kozak vd., 2014). Türk turizmi ilk olarak deniz, kum, güneş ekseninde Ege ve Akdeniz bölgelerinde yoğunlaşmıştır. Zaman içerisinde ciddi yatırımlar ve modern tesisler ile Türkiye bu turizm türünde hatırı sayılır bir yer edinmiştir. Ülkemiz uzun süredir turist sayısında dünyada ilk 10 ülke arasındaki yerini korumaktadır. Fakat Türkiye turizmden elde edilen gelirlerde ise ne yazık ki ilk on ülke arasında değildir. Bu bağlamda Türkiye'deki turizm politikalarında bir değişimin olması gerektiği üzerinde durulmaya başlanmıştır. Turistik kaynak çeşitliliğinin oldukça fazla olduğu ülkemizde ağırlıklı olarak tek bir turizm türüne (deniz, kum, güneş) odaklanılması artık eleştirilmektedir. Türkiye'ye farklı turist profillerinin çekilmesi amacıyla alternatif turizm türlerine yönelim artmıştır (Güzel, 2010; Çelik, 2018).

Alternatif turizm çeşitlerinin büyük bir kısmı ise doğa temelli turizm türlerinden oluşmaktadır. Yayla turizmi, kuş gözlemciliği, dağ turizmi gibi turizm türleri ülkemizdeki alternatif turizm türlerinde bazılardır. Bahsedilen bu turizm türleri ise esasında doğa temelli turizm çeşitleri olarak ifade edilmektedir. Doğa temelli turizm türleri açısından birçok kaynağa sahip olan Erzurum ilinde ise "turizm" kış turizmi ekseninde mevsimsellik özelliği gösterdiği görülmektedir.

Türkiye'nin turizmi 12 aya yayma stratejisi uzun yıllardır tartışılmakta ve bu konu üzerine çalışmalar devam etmektedir. Her ne kadar Türkiye için turizm ağırlıklı olarak yaz aylarında yoğunlaşsa da Erzurum ili için bu yoğunlaşma genel mevsimsel özelliklerinden dolayı kış aylarına tekabül etmektedir. Erzurum ili için Turizmi 12 aya yaymak ve kış turizm destinasyonu algısını kırmak için ilin doğa temelli başlıca turizm kaynaklarının iyi bir şekilde değerlendirilmesi ve tanitımının yapılması gerekmektedir.

Alternatif turizm türlerinin etkin bir şekilde kullanılması ile birlikte Erzurum ili de yılın 4 mevsimi turist ağırlayabilecek konuma gelebilecektir. Bu çalışmada Erzurum'un önemli doğa temelli turizm destinasyonlarından olan Narman Peri Bacalarına seyahat eden ziyaretçilerin destinasyon hakkındaki görüşleri "tripadvisor ve Google" internet siteleri üzerinden içerik analizi ile incelenmiştir. Mevcut çalışma Narman Peribacalarını ziyaret eden kişilerin destinasyonla ilgili görüşlerini belirlemeyi amaçlamaktadır.

\section{KAVRAMSAL ÇERÇEVE}

Doğa temelli turizm soyut olarak insanların estetik deneyimler, bilişsel ve ruhsal gelişim, rekreasyon yoluyla doğal ekosistemden elde ettiği maddi olmayan faydalar bütünü olarak tanımlanabilir (Assessment, 2005). Doğa temelli turizmin tanımlarından biri de aktiviteye katılımın temel amacının doğa ile ilgili turizm çeşidi olduğu görüşüdür (Matilainen ve Lähdesmäki, 2014; Fredman vd., 2012). Doğa temelli turizmin tanımında literatürde ortak bir görüş mevcut değildir. Bazı araştırmalarda doğa temelli turizm ile eko turizm benzer anlamlarda kullanılırken bazı araştırmacılar ise böyle bir tanımın yanlış olacağını, esasında iki kavramın birbirinden farklı olduğunu vurgulamaktadır. Doğa temelli turizmin ilk tanımlarında üç unsur vurgulanmaktadır. Bu unsurlar eğitim, macera ve rekreasyon olarak sıralanmaktadır (Köroğlu vd., 2012).

Doğa temelli turizm endüstrisi 4 unsur içerisinde incelenebilir. Birincisi doğal ortamları keşfetmeyi ve bilgi edinmeyi amaçlayan ekoturizm unsuru, ikincisi tehlikeye atılma, hakimiyet 
kurma, heyecan ve adrenalin elde etmeyi amaçlayan, macera turizmi unsuru, üçüncüsü ilkel, insandan yoksun destinasyonlara rekreasyon amacı ile yapılan seyahatleri içeren el değmemiş doğa turizmi unsuru ve dördüncüsü ise aile içinde güvenli bir seyahat biçimi olarak arabalı kamp turizmi unsurudur (Eagles, 1997'den akt. Cloesen, 2003).

Boo (1990) doğa temelli turizmi "görece bozulmamış veya kirlenmemiş doğal alanlara, özellikle çalışma, hayranlık veya hayranlık duyma amacıyla gerçekleştirilen seyahatlerden oluşan turizm türü" olarak tanımlamaktadır. Bu seyahatlerde manzaranın ve yabani bitkilerin, hayvanların yanı sıra mevcut kültürel durumu deneyimlemek önemli motivasyon kaynaklarıdır. Doğa temelli turizmi insanların gezerken yaptıkları faaliyetler çerçevesinde tanımlamak da mümkündür. Bu tür bir tanıma göre doğa temelli turizm tatil ile doğa etkileşimine odaklanılan ve genellikle bir geceleme içeren turizm türü olarak tanımlanmaktadır (Silvennoinen ve Tyrväinen, 2001).

Doğa turizmi, doğal alanlara yönelik gerçekleştirilen seyahatleri içermektedir. Manzara, doğal kaynaklardan yararlanma, bitki örtüsü, yaban hayatı, su gibi doğal kaynakların kullanımına dayalı turizm çeşitlerini kapsamaktadır. Doğaya dayalı turizm ise kırsal alanlarda gerçekleştirilen rekreasyon amaçlı veya macera içeren aktiviteleri içine almaktadır (Ceballos Lascurain, 1996; Kiper ve Aslan 2007). Lucas (1985) doğa temelli turizmi doğal alanların gözlemlenmesini ve doğadan zevk almayı içeren fakat doğa üzerinde ise çok az etki bırakılan turizm türü olarak ifade etmektedir.

Doğa temelli turizm, son yıllarda birçok ülke ve bölgede yerel topluluklara ekonomik faydalar sağlayarak ve böylece yoksulluğun azaltılmasına katkıda bulunarak hızlı bir büyüme yaşamıştır. Bununla birlikte, doğaya dayalı turizm bazı ekolojik sorunlara da neden olmuştur. Bu sorunlar, uygunsuz turizm planlaması, gereğinden fazla turizm tesisi inşası ve turist akışının zayıf yönetimi olarak sıralanabilir (Yuxi vd., 2020). Dünyada giderek daha fazla insan şehirlerde yaşadıkça, doğal dünyadan koptukça eşsiz deneyimleri sayesinde doğa temelli turizme olan ilgi, dünya genelinde artacağı öngörülmektedir. İnsanları doğa ile birleştiren bir turizm biçimi olarak, doğa temelli turizm daha fazla ilgiyi hak etmektedir (Zhang ve Xu, 2020).

Browne ve Hunt (2007:19) "doğaya dayalı turizmi, balık tutma, avlanma, kayak yapma, snowboard, kar motosikleti, kızak, kano, su sporları, yürüyüş, dağ bisikleti, kuş gözlemciliği, bitki gözlemciliği, kelebek gözlemciliği, yaban hayatı izleme, fotoğrafçılık ve bunun gibi pek çok rekreasyonel faaliyeti içeren" turizm türü olarak ifade etmiştir (Köroğlu ve Karaman, 2014).

\section{Erzurum İlindeki Başlıca Doğa Temelli Turizm Destinasyonları}

\section{Narman Peri Bacaları}

Doğu Anadolu bölgesindeki eşsiz jeolojik oluşumlardan biri olan Narman Peri Bacaları "Kırmızı Periler Diyarı" olarak da anılmaktadır. Yer aldığı alan âdete açık hava müzesi görünümündedir. Başlıca görsel güzelliği ve diğer peri bacalarından ayrılan özelliği ise kırmızı kum taşları ve benzer renkteki taşlardan kaynaşarak oluşmasıdır. Bu oluşumu Kapadokya'daki peri bacalarından ayıran özellik ise Kapadokya'daki peri bacalarının volkanik bir oluşum olması Narman Peri Bacalarının ise sedimanter bir yapıya sahip olması ve bulunduğu alanda gözlenen "Pliyo/Kuvaterner" tortul kayaçlarda ortaya çıkan demir elementi dolayısıyla kırmızı bir renge sahip olmasıdır (www.erzurum.ktb.gov.tr). 


\section{Narman Beş Göller}

Narman Beş Göller değişik büyüklükteki beş gölden oluşmakta olup Erzurum'a 121 Narman merkeze ise $25 \mathrm{~km}$ uzaklıktadır. Eşsiz güzellikleri ile Erzurum ilinde keşfedilmeyi bekleyen başlıca doğa temelli bakir turizm destinasyonlarındandır. Bölge kamp ve trekking meraklıları için uygundur. Beş göllere gitmek için en uygun zaman ise yaz aylarıdır (www.erzurum.ktb.gov.tr).

\section{İspir Yedigöller}

Türkiye'nin mutlaka keşfedilmesi gereken volkanik göllerinden biridir. Ovit Dağı'nın güneyinde konumlanan İspir Yedigöller dağcıların gözde mekânlarındandır. Değişik boyutlarda 11 gölden oluşan Yedigöller'e ulaşım özel araçlarla sağlanabilmektedir. Normal araçla ulaşım mümkün olmamakla birlikte arazi aracı ile stabilize yollardan bu eşsiz güzelliğe ulaşılabilmektedir (www.erzurum.ktb.gov.tr).

\section{Hinis Kanyonu}

Erzurum'un güneyinde 1720 rakımda ova üzerine konumlanmış olan Hınıs Kanyonu bakir doğa harikası yapısı ile rafting, dağcılık ve kanyon düşkünleri için uygun doğa temelli turizm destinasyonlarındandır.

\section{Çoruh Nehri}

Nehrin 260 km'si Erzurum ili sınırlarından geçmektedir. Rafting ve kano gibi su sporları için çok ideal bir nehir olmakla birlikte çok zorlu parkurlara da sahiptir. Su sporlarını sevenler için güzel bir doğa temelli turizm destinasyonudur. Erzurum'da yer alan doğa temelli turizm destinasyonlarının görselleri EK.1'de gösterilmektedir.

Erzurum ili için kış turizmine alternatif bir turizm hareketliliği oluşturma potansiyeli taşıyan doğa temelli turizm destinasyonlarının turistik çekim merkezi olarak değerlendirilmesi bölgeye turist varışlarını artıracağı gibi turizmden elde edilen ekonomik geliri de olumlu yönde etkileyecektir. Bunun yanı sıra Erzurum'da doğa temelli turizm destinasyonlarının turizm amaçlı değerlendirilmesi ile birlikte turizmden elde edilen gelirden kırsal kesimde yaşayan yerel halk da yararlanabilecektir. Bu durum kırdan kente göçü de azaltabilecektir.

\section{YÖNTEM}

Bu çalışma nitel araştırma desenlerinden olan durum çalışması şeklinde hazırlanmıştır. Durum çalışmaları daha ziyade tek bir durum veya olayın detaylıca incelendiği, verilerin sistematik şekilde bir araya getirildiği ve gerçek ortamda ne olduğunun araştırıldığı bir yöntemdir (Subaşı ve Okumuş, 2017: 420-422). Bu çalışmada örnekleme yöntemi olarak ölçüt örnekleme kullanılmıştır. Elde edilen verilerin analizi için NVIVO 12 programından faydalanılmıştır. Ziyaretçilerin ortak veya benzer yorumları dikkate alınarak kodlama işlemi gerçekleştirilmiştir. Ziyaretçilerin yorumları araştırmaya dâhil edilirken, yazım yanlışları düzeltilmemiştir. Sadece harf hataları ile ilgili küçük düzeltmeler yapılmıştır. 


\section{Araştırmanın Amacı ve Kapsamı}

Bu araştırma Erzurum'un doğal güzelliklerinden biri olan Narman Peri Bacalarına seyahat eden ziyaretçilerin destinasyon ile ilgili görüşlerini belirlemeyi amaçlamaktadır. Alan yazını incelendiğinde Narman Peri Bacaları ile ilgili ziyaretçi deneyimleri ve görüşlerini içeren çalışmalara rastlanmamıştır. Araştırmayı hazırlayan yazarın Narman Peri Bacalarını ziyareti sonrasında destinasyonun turistik ürün olarak yeterince değerlendirilemediği probleminden yola çıkılarak bu araştırmaya başlanmıştır.

\section{Araştırmanın Evreni ve Örneklemi}

$\mathrm{Bu}$ araştırmanın evrenini Erzurum Narman Peri Bacalarına seyahat ederek "tripadvisor ve Google" üzerinden deneyimlerine yönelik yorum yapan ziyaretçiler oluşturmaktadır. Araştırmanın hazırlanmaya başlandığı dönemde bahsedilen internet siteleri üzerinden Narman Peri Bacaları hakkında yapılan yorum sayısı 140'tır. Araştırmada veri olarak kullanılan yorumlar 22.06.2020 tarihinde toplanmıştır.

\section{Araştırmanın Sınırlılıkları}

Narman Peri Bacaları ile ilgili yabancı dilde yapılan yorumların sayısı oldukça sınırlı düzeydedir. Bu yorumları yapan ziyaretçilerin kullanıcı adları da Türkçe olduğu görülmüştür. Dolayısıyla bu çalışmada Yerli, yabancı turist görüşleri ile ilgili bir ayrım yapılmamıştır.

\section{BULGULAR}

Narman Peri Bacalarını ziyaret eden kişilerin Tripadvisor ve Google üzerinden bıraktıkları yorumlar incelendiğinde toplam 88 yorumun bölge hakkında olumlu izlenimler içermekte olduğu görülmüştür. Olumlu görüşler içeren bu yorumlardan $44^{\prime}$ ü Narman Peri Bacalarını ziyaret etmemiş olan kişilere bölgeyi ziyaret etmeleri için tavsiye içeren yorumlardan oluşmaktadır. Diğer 44 yorum ise bölgeyi öven, ziyaretçilerin bölgeden memnuniyetini belirten görüşleri içermektedir. Katılımcıların bölgeye yönelik olumlu görüşlerinde, bölgenin doğal olduğu ve etkileyici manzaralar sunduğu üzerinde ağırlıklı olarak durulmuştur. 
- Mutlaka görülmesi gereken bir yer

- Harika bir yer gezilip görülmesi gereken

- Mutlaka görülmeli

- Doğal manzarasıyla görülmeğe değer güzel yerler

- Görülmeye değer bir yer.

- Kesinlikle gelip görülmeli tam bir doğa harikast.

- Gidip görmeye değer

- Eğlenceli bir mekân yolunuz düşerse bi gezin zaten yol kenarı hemen

- Tertemiz bir hava yemyeşil bir doğa adeta cennetten bir köşe var Narman'da. Gezmeden görmeden dönme...

- Görüntü gerçekten bir doğa harikası. Alan gayet geniş görülmeye değer

- Muhteşem doğal güzellikleri ile sizi kucaklayan bu yeri mutlaka ziyaret edin.

- Gezin bence Anadolu'daki görülecek yerlerden
- Dadaşlar diyarımızın gizli güzellikleri

- Çok şirin bir yer

- Doğa harikası

- Doğal manzarali bir yer

- Çok büyüleyici çok güzel manzara

- Çok harika

- Doğunun eşsiz güzelliklerinden biri.

- Nefis.

- Gerçekten büyüleyici

- Doğa harikası

- Süper

- Çok güzel

- Fotoğraf çekmek için çok güzel

- Doğanın fotoğrafinı çekmek için doğal manzara var, güzel ve harika.

- Muhteşem bir doğa mucizesi

- Muhteşem manzarasi

- Açkçası doğallığı temizliği çevresi tamamen bakir

- Doğa harikası bir mekân

- Bir doğa harikasi

- Toprağin aşınmasiyla oluşmuş doğal, güzel bir ver

\section{Şekil 1. Ziyaretçilerin Narman Peri Bacaları hakknndaki olumlu izlenimleri}

Şekil 1.'de ziyaretçilerin destinasyon ile ilgili yorumları incelenerek olumlu izlenim ana teması oluşturulmuştur. Bu ana tema ise tavsiye ve olumlu duygular olarak iki alt kategoriden oluşmaktadır. Tavsiye kategorisinde yer alan "yeşille kırmızının birbirine sarıldığı bu kadar güzel bir yere gitmek sizi rahatlatacaktır, ilginç bir doğa harikası yakınlardaysanız görmeden geçmemek gerek, coğrafi olarak oluşan bu doğal eserler kesinlikle görülmeye değer harika bir yer, gezilip görülmesi gereken tamamen doğal olarak bırakılmış, sessizliğine hayran kalacağını, eşi dostu misafiri alıp gezmelik turistik bir yer görmeye değer" vb. yorum içeriklerinden ziyaretçilerin bölgeyi özellikle doğal çekiciliklerini de vurgulayarak ziyaret için tavsiye ettikleri anlaşılmaktadır.

Olumlu izlenimler alt kategorisinde yer alan "Fotoğraf çekmek için çok güzel, doğanın fotoğrafını çekmek için doğal manzara var, güzel ve harika, muhteşem bir doğa mucizesi, muhteşem manzarası açıkçası doğallığı temizliği çevresi tamamen bakir, doğa harikası bir mekân, bir doğa harikası, toprağın aşınmasıyla oluşmuş doğal, güzel bir yer" vb. yorum içeriklerinden ziyaretçilerin bölgeye yönelik olumlu izlenimler taşıdıkları anlaşılmaktadır. 


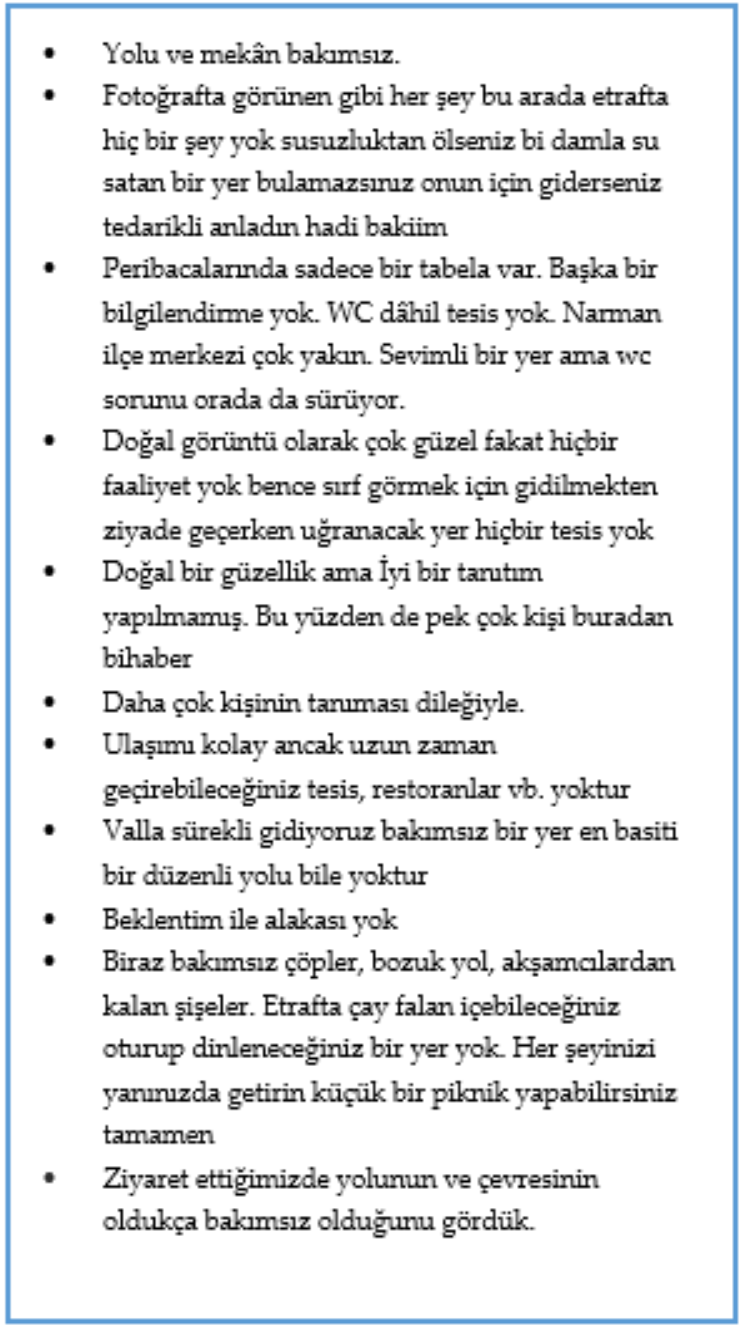

\section{Ziyaretçilerin Bölgeye Yönelik Eleştirileri}

- Güzel bir yer ama belediye ilgilenmiyor ufak bir tabela var sola dōnüp iki tur atyorsun bazı yerlere grafiti yapulmuş.

- Acilen tanutuma ve tesisleșmeye ihtiyacı var.

- Güzel bir yer fakat ilgilenilmesi gerekiyor.

- Tarutilmasi gerekiyor

- Tanutımı hiç yapılamuyor.

- Bir tesis ihtiyacı var. Ama doğal güzelliği bozmadan

- Kesinlikle tanutuma ve bakuma ihtiyac1 var

- Hiç turist adına bir șey yok iyi değerlendirilmemiș ziyarete gelenler için cafe restoran tarzı yerler açlması gerekli belediye bu konuda hiç bir șey yapmamus

- Çok güzel yerler çok beğendim tek sorun Narman'dan sonra herhangi bir levha vs olmaması sadece yol kenarmda var biz navigasyonla bulduk belediye bu konuda daha iyi olabilir

- Yalnuz böyle güzel bir yerinde Erzurum belediyesi tarafundan tabela bile yenilememis olması büyük hayal kurıklığı. Araçlan dahi yol kenarma park etmek zorunda kalyyoruz.

- Devlet el atmah yani restoran vs. İsmi İle de Kapadokya mi olmall.

- Kimseler bilmiyor Avrupalunn elinde olsa ziyaret rekoru kınlır ama belediye yol dahi yapmamus bize fazla olan bir yer

- El değmemişliğiyle de güzel olsa da daha turistik hale getirilebilir

- Acilen tanutuma ve tesisleşmeye ihtiyacı var.

\section{Ziyaretçilerin Yöneticilere Yönelik} Eleştirileri ve Tavsiyeleri

\section{Şekil 2. Ziyaretçilerin Narman Peri Bacaları Destinasyonuna ve Yöneticilere Yönelik Eleştirileri}

Şekil 2.'de ziyaretçilerin yorumlarından elde edilen eleştiri ana teması görülmektedir. Eleştiri ana teması bölgeye yönelik eleştiriler ve yöneticilere yönelik eleştiri ve tavsiyeler alt kategorilerinden oluşmaktadır.

Narman Peri Bacalarına seyahat eden ziyaretçilerin destinasyon hakkındaki eleştiri ve olumsuz görüş içeren yorumlarının sayısı toplam otuzdur. Bu eleştirilerden 11'i destinasyona yönelik iken diğer 19 eleştiri ise idarecilere yönelik olarak iletilmiştir. Narman Peri Bacalarına seyahat eden ziyaretçilerin destinasyona yönelik eleştirileri genel olarak, destinasyonun ulaşımı, destinasyondaki tesis eksiklikleri ve tanıtım eksikliklerine yönelik olmuştur.

Narman Peri Bacalarına seyahat eden ziyaretçilerin idarecilere yönelik eleştiri ve tavsiyeleri ise tanıtım eksikliği, bunu gidermek için bölgenin tanıtıma ihtiyacı olduğu, tesis eksikliği ve bunu gidermek için acil birtakım tesislerin (wc., kafe, restoran vb.) yapılması gerektiği, bölgenin yolunun bozuk ve yönlendirme levhalarının eksik olduğu ve bunu gidermek için yollarının bakımının yapılması ve yönlendirme levhalarının yerleştirilmesi gerektiği şeklindeki yorumlardan oluşmuştur. 


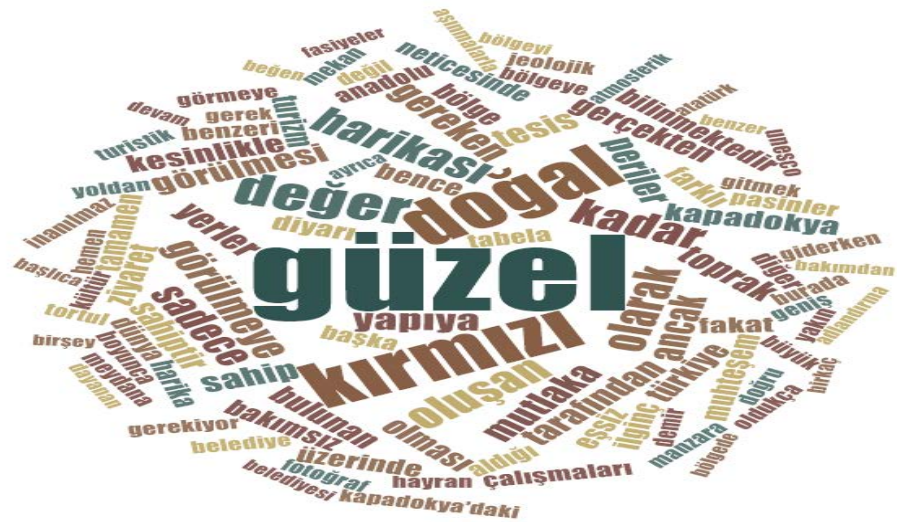

Şekil 3. Narman Peri Bacaları Ziyaretçi Yorumları Kelime Bulutu

Şekil 3'te gösterilen kelime bulutu, ziyaretçilerin Narman Peri Bacaları ile ilgili deneyimlerini içeren yorumlarından NVIVO 12 programı kullanılarak oluşturulmuştur. Güzel, doğal, harika gibi bölge hakkında olumlu çağrışımlar yapan kelimeler ön plana çıkmıştır. Bunun yanı sıra kırmızı kelimesi de Narman Peri Bacalarının doğal oluşum rengi olarak kelime bulutunda ön sıralarda belirmiştir.

\section{SONUÇ ve ÖNERILER}

Erzurum'un doğal güzelliklerinden biri olan Narman Peri Bacalarına seyahat eden ziyaretçilerin deneyimlerini içeren yorumların içerik analizi ile incelendiği bu çalışmada genel olarak şu sonuçlara ulaşılmıştır:

Narman Peri Bacaları ziyaretçileri memnun edecek düzeyde doğal çekicilikleri bulunan bir destinasyondur. Narman Peri Bacaların ziyaret edenler genel olarak olumlu deneyimlerle ayrılırken başka insanlara da bölgeyi ziyaret için sosyal medya araçlarıyla tavsiye vermektedir. Narman Peri Bacaları her ne kadar doğal çekicilikleri bünyesinde taşısa da turistik bir ürün olarak değerlendirilebilecek alt ve üstyapı imkânlarına yeterli düzeyde sahip değildir. Ziyaretçilerin yorumlarından ve araştırmayı yapan yazarın kendi deneyimlerinden yola çıarak destinasyonda ziyaretçilerin temel ihtiyaçlarını (yeme içme, büfe, lavoba vb.) karşılamaya yönelik tesislerin bulunmadığı anlaşılmaktadır. Narman Peri Bacalarına seyahat eden ziyaretçiler yol, yönlendirme levhaları gibi ulaşıma yönelik eksikliklerin olduğunu belirtmektedir. Peri bacalarına ulaşımda bir takım olumsuzluklar dikkat çekmektedir. Narman Peri bacalarının bulunduğu alan ziyaretçiler tarafından piknik vb. amaçlarla kullanabilmektedir. Bu durumun görüntü ve çevre kirliliklerine neden olabileceği düşünülmüştür.

Peri bacalarının bulunduğu alana ziyaretçiler serbestçe ve ücretsiz denetim olmadan girebilmektedir. $\mathrm{Bu}$ durumun destinasyonu ziyaret edenler için güvenlik sorunları doğurabileceği düşünülmüştür. Ziyaretçiler Peri bacalarının tanıtımının iyi yapılmadığını belirtmektedir. Destinasyonda tesisleşme olmadığından ziyaretçiler araçlarını park edecek alan bulmakta sıkıntı yaşayabilmektedir. Araçlarını yol kenarında bırakmak mecburiyetinde kalmaktadırlar. Bu durum trafiği aksatıcı ve kazalara sebep olabilecek riskleri taşıdığı öngörülmüştür. 
Ziyaretçilerin deneyimlerinden elde edilen yorumlar doğrultusunda şu öneriler geliştirilmiştir: Bölgeye lavabo, tuvalet, kafe vb. temel ihtiyaçlara yönelik doğal çevreye uyumlu tesislerin kazandırılması gerekmektedir. Ziyaretçilerin bölgeye güvenli ve rahat ulaşımının sağlanması için yol bakım çalışmaları yapılmalı ve yönlendirme levhaları ile ziyaretçilerin bölgeyi daha rahat bulmaları sağlanmalıdır. Bölgede araçların park edebileceği güvenli alanlar oluşturulmalıdır. Ziyaretçiler özellikle bölgeye yönelik belediye hizmetlerini eleştirmektedir. İlgili yerel yönetim bölgenin tanıtımını ve doğal çevreye uygun tesisleşme çalışmalarını üstlenmelidir.

Erzurum kış turizmi ile ön plana çıkmış bir ilimizdir, fakat Erzurum'da doğa temelli birçok alternatif turizm çekicilikleri bulunmaktadır. Bunlardan birisi de Narman Peri Bacalarıdır. Bu doğal güzelliğin tanıtımının yeterli düzeyde olmadığı anlaşılmaktadır. Henüz Peri Bacalarının turistik cazibe merkezi olarak potansiyelinin tam olarak kullanılmadığı düşünülmektedir. Buna rağmen ziyaretçiler bölgenin doğal güzelliklerinden etkilenerek olumlu deneyimler ile alandan ayrılmaktadır. Fakat ilgili sosyal medya araçlarından da eleştirilerini özelikle idarecilere yöneltmektedir. Narman Peri Bacalarının turistik bir ürün olarak daha etkin kullanılabilmesi için tanıtım çalışmalarına hız kazandırılması tavsiye edilmektedir.

Narman Peri Bacalarına yönelik alan yazınında ziyaretçi görüşlerini içeren çalışmalara rastlanmamıştır. Erzurum'un kırsal turizm potansiyelinin, ekoturizm potansiyelinin incelendiği kavramsal çalışmalarda Narman Peri Bacalarına da değinildi görülmüştür (Cengiz ve Akkuş, 2012; Küleçki ve Toy, 2017; Küleçki vd., 2019). Fakat bölge ziyaretçileri üzerine yapılmış bir çalışmaya rastlanmamıştır. Narman Peri Bacalarına yönelik gelecekteki araştırmalarda ise anket veya yüz yüze görüşme yönteminin kullanılması ile ziyaretçilerin görüşlerinin belirlenmesi önerilmektedir.

\section{Kaynaklar}

Assessment, M. E. (2005). Millennium Ecosystem Assessment. Ecosystems and Human Wellbeing: A Framework for Assessment. Island Press: Washington.

Boo, E. (1990). Ecotourism: The Potentials and Pitfalls. Washington, DC: World Wildlife Fund.

Browne, S. A. and Hunt, L. M. (2007). Climate change and nature-based tourism, outdoor recreation, and forestry in ontario: potential effects and adaptation strategies, Queen's Printer: Canada.

Ceballos-Luscurain, H. (1996). Tourism, Ecotourism and Protected Areas: The State of Nature Based Tourism Around the World and Guidelines for Its Development, IUCN: Switzerland and Cambridge, UK.

Cloesen, U. (2003) Approaches Towards Nature-Based Tourism Policies in Australia and New Zealand, Asia Pacific Journal of Tourism Research, 8 (1), $72-77$.

Cengiz, G. ve Akkuş, Ç. (2012). Kırsal Turizm Kapsamında Yöre Halkının Kalkındırılması: Erzurum Örneği, Karamanoğlu Mehmet Bey Üniversitesi Sosyal ve Ekonomik Araştırmalar Dergisi, 14 (22): 61-74.

Çelik, S. (2018). Alternatif turizm, Uluslararası Sosyal Araştırmalar Dergisi, 11(56), 193-204.

Fredman, F., Wall-Reinius, S. and Grundén, A. (2012). The Nature of Nature in Nature-Based Tourism, Scandinavian Journal of Hospitality and Tourism, 12(4), 289-309. 
Güzel,Ö.F. (2010). Turistik Ürün Çeşitlendirmesi Kapsamında Yeni Bir Dinamik: İnanç Turizmi, Süleyman Demirel Üniversitesi Vizyoner Dergisi, 2(2), 87-100.

https://erzurum.ktb.gov.tr/TR-174617/narman-peri-bacalari.html 01.07.2020 tarihinde alınmıştır. https://erzurum.ktb.gov.tr/TR-174673/narman-bes-goller.html 01.07.2020 tarihinde alınmıştır. https:/erzurum.ktb.gov.tr/TR-174619/ispir-yedigoller.html 01.07.2020 tarihinde alınmıştır.

https://www.google.com/search?q=narman+peri+bacalar\%C4\%B1+yorumlar\&oq=narman+peri+ bacalar\%C4\%B1+yorumlar\&aqs=chrome.0.69i59j69i57j69i60.5317j1j9\&sourceid=chrome\&ie=UTF -8\#1rd=0x406ecccbf4f8e811:0xceadd010931db860,1 22.06.2020 tarihinde alınmıştır.

https://www.tripadvisor.com.tr/Attraction_Review-g297996-d10330617-Reviews

Narman_Peribacalari-Erzurum.html 22.06.2020 tarihinde alınmıştır.

Kiper, T. ve Arslan, M. (2007). Anadolu'da Doğa Turizmi Kapsamında Doğa Yürüyüşü Güzergâhlarının Belirlemesinde Örnek Bir Çalışma, Tekirdă̆ Ziraat Fakültesi Dergisi, 4 (2), 165174.

Kozak, N., Kozak, A. M ve Kozak, M (2014). Genel Turizm: İlkeler ve Kavramlar, Detay Yayıncilik: Ankara.

Köroğlu, Ö. ve Karaman, S. (2014). Doğaya Dayalı Turizm Faaliyetlerinin Gelişiminde Toplum Temelli Doğal Kaynak Yönetiminin Önemi, Sosyal ve Ekonomik Araştırmalar Dergisi, 16 (26): 95106.

Köroğlu, Ö., Köroğlu, A. ve Alper, B. (2012). Doğaya Dayalı Gerçekleştirilen Turizm Faaliyetleri İçerisinde Turist Rehberlerinin Rolleri Üzerine Bir İnceleme, Karamanoğlu Mehmet Bey Üniversitesi Sosyal ve Ekonomik Araştırmalar Dergisi, 14 (22): 131-139.

Küleçki, E. A.ve Toy, S. (2017). Erzurum İli UNITO Bölgesi Ekoturizm Faaliyetlerinin İlçelere Göre Dağılımının Değerlendirilmesi, Yüzüncü Yıl Üniversitesi Sosyal Bilimler Enstitüsü Dergisi, 3 (1), 1-17.

Küleçki, E. A., Sezen, I. ve Gencer, S. (2019). Erzurum Kentinin Turizm Potansiyelin Belirlenmesine Yönelik Bir Araştırma, Kent Kültürü ve Yönetimi Hakemli Elektronik Dergi, 12 (4), 714-728.

Lucas, P.H.C. (1985). How Protected Areas Can Help Meet Society's Evolving Needs, $72-77$ in J.A. McNeely, and K.R. Miller, eds, National parks, conservation, and development, Smithsonian Institution Press: Washington.

Matilainen, A. and Lähdesmäki, M. (2014). Nature-based Tourism in Private Forests: Stakeholder Management Balancing the Interests of Entrepreneurs and Forest Owners? Journal of Rural Studies, $35,70-79$.

Silvennoinen, H., and Tyrväinen, L. (2001). The Demand for Nature-Based Tourism in Finland And Environmental Expectations of The Clients. In: T. Sievänen (Ed.), Outdoor recreation 2000. Working papers of the Finnish Forest Research Institute 802, 112-127.

Subaşı, M. ve Okumuş, K. (2017). Bir Araştırma Yöntemi Olarak Durum Çalışması, Atatürk Üniversitesi Sosyal Bilimler Enstitüsü Dergisi, 21 (2), 419-426.

Yuxi, Z. and Linsheng, Z. (2020). Identifying Conflicts Tendency Between Nature-Based Tourism Development and Ecological Protection in China, Ecological Indicators, 109, 1-14. 
Zhang, Q. and Xu, H. (2020). Understanding Aesthetic Experiences in Nature-Based Tourism: The Important Role of Tourists' literary Associations, Journal of Destination Marketing \& Management, $15,1-12$. 
EK 1. Erzurum'daki Doğa Temelli Turizm Destinasyonlarının Görselleri

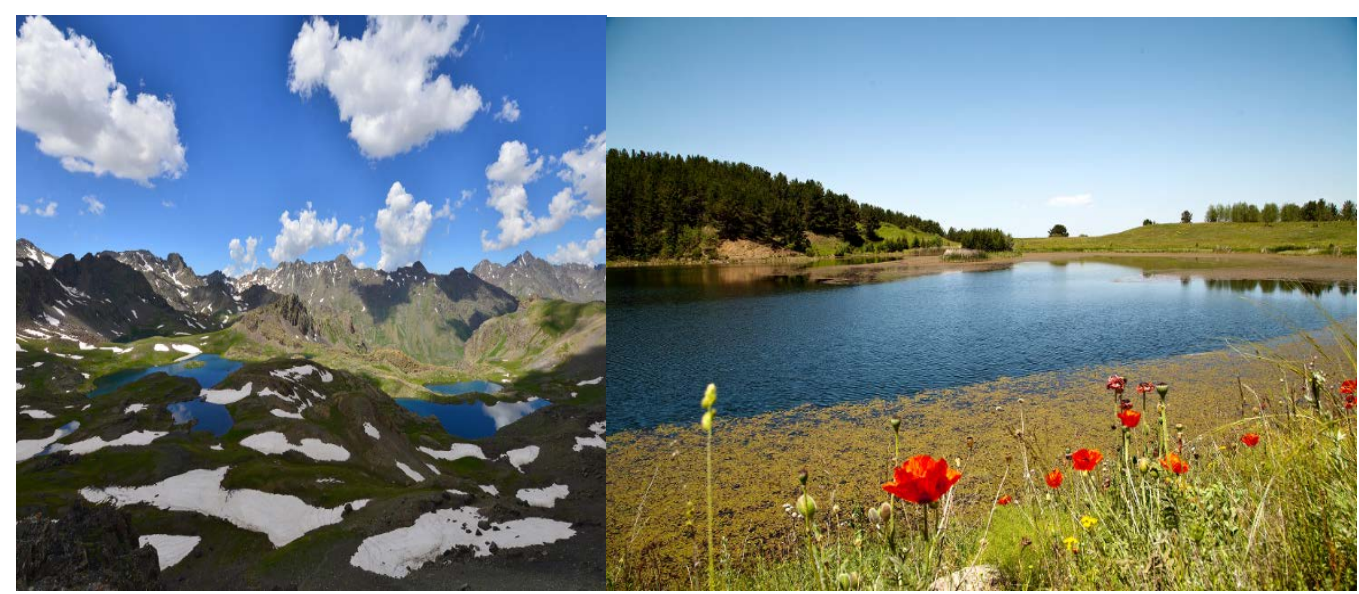

İspir Yedigöller

Narman Beş Göller

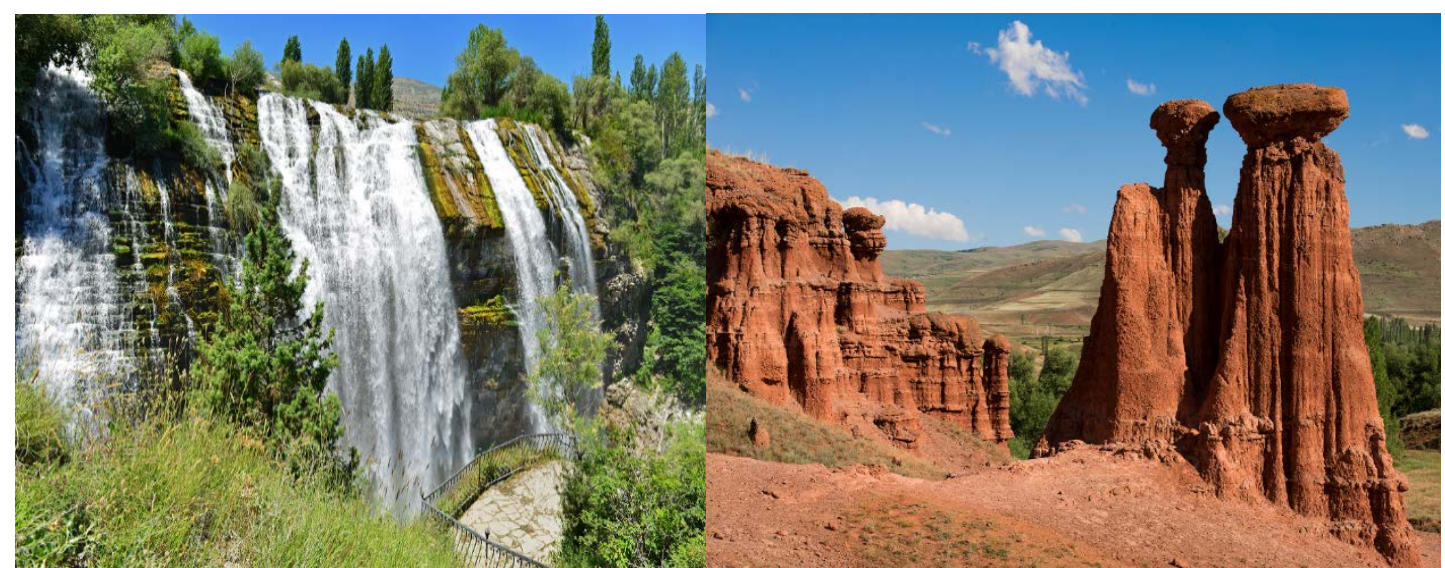

Tortum Şelalesi

Narman Peri Bacaları

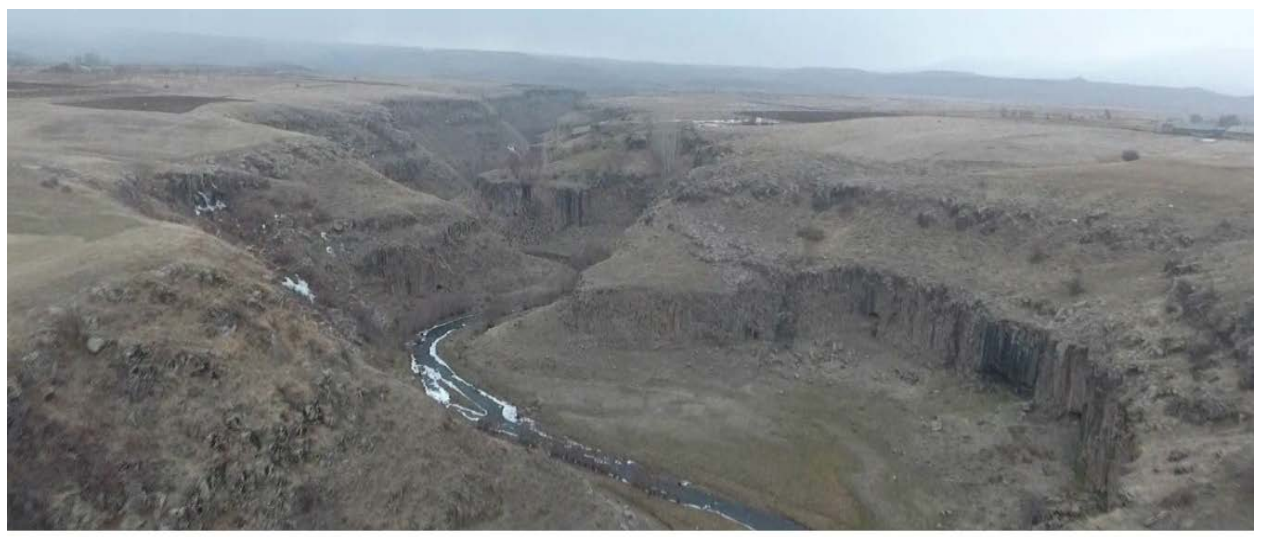

Hınıs Kanyonu

Not: Resimler Erzurum İl Kültür ve Turizm Müdürlügünün resmi internet sitesinden alınmıştır. 